\title{
Effects of gravitational acceleration on cardiovascular autonomic control in resting humans
}

\author{
Timothée Fontolliet • Vincent Pichot • \\ Guglielmo Antonutto $\cdot$ Julien Bonjour $\cdot$ Carlo Capelli $\cdot$ \\ Enrico Tam · Jean-Claude Barthélémy · Guido Ferretti
}

Received: 15 April 2014 / Accepted: 26 January 2015 / Published online: 14 February 2015

(C) Springer-Verlag Berlin Heidelberg 2015

\begin{abstract}
Purpose Previous studies of cardiovascular responses in hypergravity suggest increased sympathetic regulation. The analysis of spontaneous heart rate variability (HRV) parameters and spontaneous baroreflex sensitivity (BRS) informs on the reciprocal balance of parasympathetic and sympathetic regulations at rest. This paper was aimed at determining the effects of gravitational acceleration $\left(a_{\mathrm{g}}\right)$ on HRV and BRS.

Methods Eleven healthy subjects (age $26.6 \pm 6.1$ ) were studied in a human centrifuge at four $a_{\mathrm{g}}$ levels $(1,1.5,2$ and $2.5 \mathrm{~g}$ ) during 5-min sessions at rest. We evaluated spontaneous variability of R-R interval (RR), and of systolic and diastolic blood pressure (SAP and DAP, respectively), by
\end{abstract}

Communicated by Massimo Pagani.

T. Fontolliet $(\square) \cdot$ J. Bonjour $\cdot$ G. Ferretti

Département de Neurosciences Fondamentales, Université de

Genève, 1, Rue Michel Servet, 1211 Geneve 4, Switzerland

e-mail: timothee.fontolliet@unige.ch

T. Fontolliet · V. Pichot · J.-C. Barthélémy

EA SNA-Epis 4607, Université Jean-Monnet, Saint-Étienne,

France

G. Antonutto

Dipartimento di Scienze e Tecnologie Biomediche, Università di

Udine, Udine, Italy

C. Capelli · E. Tam

Dipartimento di Scienze Neurologiche e del Movimento,

Università di Verona, Verona, Italy

G. Ferretti

Dipartimento di Scienze Cliniche e Sperimentali, Università di

Brescia, Brescia, Italy power spectral analysis, and BRS by the sequence method, using the BRSanalysis ${ }^{\circledR}$ software.

Results At $2.5 \mathrm{~g}$, compared to $1 \mathrm{~g}$, (1) the total power $\left(P_{\mathrm{TOT}}\right)$ and the powers of LF and HF components of HRV were lower, while the LF/HF ratio was higher; (2) normalized units for LF and HF did not changed significantly; (3) the $P_{\mathrm{TOT}}, \mathrm{LF}$ and HF powers of SAP were higher; (4) the $P_{\text {TOT }}$ and LF power of DAP were higher; and (5) BRS was decreased.

Conclusions These results do not agree with the notion of sympathetic up-regulation supported by the increase in HR and DAP (tonic indices), and of SAP and DAP LF powers (oscillatory indices). The $P_{\text {TOT }}$ reduction leads to speculate that only the sympathetic branch of the ANS might have been active during elevated $a_{\mathrm{g}}$ exposure. The vascular response occurred in a condition of massive baroreceptive unloading.

Keywords Heart rate variability $\cdot$ Arterial blood pressure $\cdot$ Baroreflexes $\cdot$ Human centrifuge

$\begin{array}{ll}\text { Abbreviations } \\ a_{\mathrm{g}} & \text { Gravitational acceleration } \\ \text { ANOVA } & \text { Analysis of variance } \\ \text { ANS } & \text { Autonomic nervous system } \\ \text { BRS } & \text { Baroreflex sensitivity } \\ \text { DAP } & \text { Diastolic arterial pressure } \\ \text { FFT } & \text { Fast fourier transform } \\ G_{z} & \text { Vertical acceleration } \\ \text { HR } & \text { Heart rate } \\ \text { HF } & \text { High frequency } \\ \text { HFnu } & \text { Normalized high frequency } \\ \text { HRV } & \text { Heart rate variability } \\ \text { LF } & \text { Low frequency } \\ \text { LFnu } & \text { Normalized low frequency }\end{array}$




$\begin{array}{ll}\text { LF/HF } & \text { Low and high frequency ratio } \\ \text { MAP } & \text { Mean arterial pressure } \\ \text { MSNA } & \text { Muscle sympathetic nerve activity } \\ P_{\text {TOT }} & \text { Total power } \\ R_{\mathrm{P}} & \text { Total peripheral resistance } \\ \text { SAP } & \text { Systolic arterial pressure } \\ \text { VLF } & \text { Very low frequency }\end{array}$

\section{Introduction}

A variety of studies have examined tolerance to high gravitational acceleration $\left(a_{\mathrm{g}}\right)$, both at rest and during exercise. Several cardiopulmonary variables were investigated, such as cardiac output, blood pressure, stroke volume and pulmonary diffusing capacity or oxygen consumption (Bjurstedt et al. 1968; Bonjour et al. 2010, 2011; Burton and Smith 2011; Girardis et al. 1999; Linnarsson and Rosenhamer 1967, 1968; Pendergast et al. 2012; Rohdin and Linnarsson 2002). These studies showed that at rest, when $a_{\mathrm{g}}$ [vertical acceleration $\left(G_{z}\right)$ to be more specific] was increased, heart rate (HR), total peripheral resistance $\left(R_{\mathrm{p}}\right)$, mean arterial pressure (MAP) and ventilation increased linearly with it, whereas stroke volume and pulmonary diffusing capacity decreased in a linear fashion.

Tools for indirect non-invasive assessment of the autonomic nervous system (ANS) regulation, including the analysis of spontaneous heart rate variability (HRV) parameters and spontaneous baroreflex sensitivity (BRS), are thought to inform on the reciprocal balance of parasympathetic and sympathetic regulations at any given time, at rest (Drouin et al. 1997; Pagani et al. 1986; Rosenstock et al. 1999; Task force of the European Society of Cardiology and the North American Society of Pacing and Electrophysiology 1996). These tools were applied in microgravity (Ferretti et al. 2009; Fortrat et al. 2001; Hirayanagi et al. 2004; Hughson et al. 1995; Traon et al. 1998), along with the study of peripheral sympathetic nerve activity and catecholamine concentration (Arbeille et al. 2008; Barbe et al. 1999; Christensen et al. 2005; Eckberg and Neurolab Autonomic Nervous System Team 2003; Edgell et al. 2007; Ertl et al. 2002; Ferretti et al. 2009; Kamiya et al. 2004; Tanaka et al. 2013). In contrast, the studies carried out in hypergravity are scanty, and only stress hormones and the effects of beta-adrenergic blockade were analysed (Bjurstedt et al. 1974; Schneider et al. 2008; Strempel et al. 2008). These studies coherently suggest an increased regulation of the sympathetic system.

On this basis, we carried out the present study, the aim of which was to determine the effects of $a_{\mathrm{g}}$ on HRV and baroreflex sensitivity (BRS).

\section{Methods}

Subjects

Eleven young healthy subjects participated in the study. They were $26.6 \pm 6.1$ years old, their body mass was $76.5 \pm 8.2 \mathrm{~kg}$ and they were $180 \pm 5.1 \mathrm{~cm}$ tall. The aims, design, protocol and method of the study were thoroughly described to the volunteers who agreed by signing an informed consent form. They had no history of cardiopulmonary disease and were not taking medications at the time of the experiments. They had to abstain from coffee and from nicotine-containing products during $24 \mathrm{~h}$ before the experiment. The study was approved by the Regional Ethical Board, Stockholm, and it was conducted in accordance with the 1964 Declaration of Helsinki on experiments on human subjects.

\section{Set-up}

Experiments took place in the human centrifuge at the Karolinska Institute, Stockholm, Sweden. The subjects were located in the centrifuge gondola, sitting on a seat, which could be adjusted to be perpendicular to the resultant of the normal $g$ vector and the centrifugal $g$ vector. They were secured on the seat by a five-point safety belt, and their feet were fixed on an electrically braked cycle ergometer that was located in front of the seat. The rotational radius of the centrifuge was $7.2 \mathrm{~m}$ at the middle of the support surface. Slip rings at the centre of rotation allowed for audiovisual monitoring, power supply and transmission of physiological signals between the gondola and a control room.

\section{Measurements}

An electrocardiogram (ECG) was recorded and monitored throughout the experiments in order to look for abnormalities and to determine HR. Continuous recordings of arterial pulse pressure were obtained at a fingertip of the right arm by means of a non-invasive cuff pressure recorder (Portapres, TNO, Eindhoven, The Netherlands). The sensed fingertip was kept at the heart level. Systolic and diastolic blood pressure (SAP and DAP, respectively) values were obtained from each pulse pressure profile, using the Beatscope $^{\circledR}$ software package (FMS, Amsterdam, The Netherlands). Beat-by-beat mean arterial pressure (MAP) was computed as the integral mean of each pressure profile, using the same software package.

It is noteworthy that the blood pressure profiles in this study were obtained from non-invasive recordings from a peripheral finger artery. The pulse wave characteristics of a peripheral artery are, in fact, remarkably different from 
Fig. 1 Schematic illustration of subject's positioning in the spinning centrifuge. The subject seated in the centrifuge gondola is exposed to acceleration equal to $1 / \cos \alpha, \alpha$ being the angle formed by the vertical axis and the gondola axis

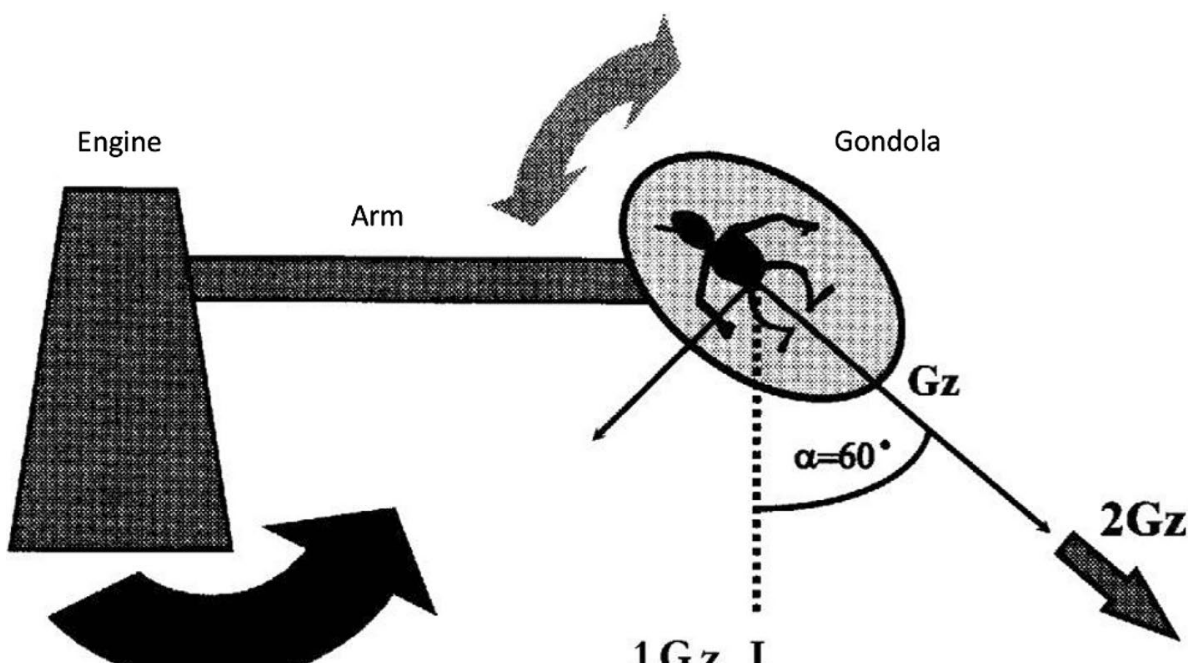

$1 \mathrm{Gz} \mathrm{I}$ those of a central artery (Remington and Wood 1956), and different absolute SAP and DAP values are obtained (Azabji-Kenfack et al. 2004). Possible vasoconstriction (see "Results") may blunt the pressure response as $a_{\mathrm{g}}$ is increased, although the growth of MAP with $a_{\mathrm{g}}$ was clearly demonstrated not only with the present method (Bonjour et al. 2011) but also with an invasive method (Linnarsson and Rosenhamer 1968).

\section{Protocol}

Experiments were conducted at four $a_{\mathrm{g}}$ levels, corresponding to $1,1.5,2$ and $2.5 \mathrm{~g}$. Control experiments at $1 \mathrm{~g}$ were also carried out in the gondola, using the same experimental set-up as for the hypergravity experiments. After having reached the appropriate spinning speed, $5 \mathrm{~min}$ at rest were allowed, during which all investigated parameters were continuously recorded. Then the protocol continued with an exercise session, which was carried out for other purposes (Bonjour et al. 2010). At the end of the exercise, the gondola was decelerated and parked. The reported values were obtained as the mean of all the beat-by-beat values determined during the last 2-3 min of the rest of each session with the centrifuge spinning. Overall, each subject underwent 16 experimental sessions as four different gravitational accelerations and four different workloads were used, which provided four repetitions of resting recordings at each investigated $a_{\mathrm{g}}$ for the sake of this study. A schematic drawing of the centrifuge arrangement during spinning, with indication of the gravitational vector, is shown in Fig. 1 .

\section{Data treatment}

Examples at 1 and $2.5 \mathrm{~g}$ of the recordings and relevant analysis carried out in this study are presented in Fig. 2 for HRV and Fig. 3 for arterial pressure variability. After construction of the time series of $\mathrm{R}$-wave to $\mathrm{R}$-wave interval (RR), SAP and DAP from the continuous recordings of ECG and pulse pressure profiles, Fast Fourier transform (FFT) was used to evaluate spontaneous variability of RR, SAP and DAP (Pagani et al. 1986). The total power $\left(P_{\mathrm{TOT}}\right)$ of RR, SAP and DAP variabilities, corresponding to variance, was initially obtained. Subsequently, the powers of the low $(0.03-0.14 \mathrm{~Hz})$ - and the high $(0.15-0.5 \mathrm{~Hz})$-frequency spectral components (low frequency, LF, and high frequency, HF, respectively) were computed and expressed in absolute units $\left(\mathrm{ms}^{2}\right)$, and their ratio (LF/HF ratio) was calculated. The very low frequency (VLF) component was neglected, as they are known to reflect the long-term regulatory mechanisms which are not relevant in our study. Moreover, our data were obtained during 5-min sessions, a condition in which the analysis of the very low frequency component provides dubious results (Task force of the European Society of Cardiology and the North American Society of Pacing and Electrophysiology 1996). Normalized LF and HF (LFnu and HFnu, respectively) were also computed as

$\frac{\mathrm{LF} \times 100}{P_{\mathrm{TOT}}-\mathrm{VLF}}$

and expressed in normalized units (nu) (Malliani et al. 1991; Pagani and Malliani 2000). The LF and HF central frequencies were also computed as the frequencies corresponding to the peak power value within the LF and HF bands of the HRV spectra.

The spontaneous baroreflex sensitivity (BRS, expressed in $\mathrm{ms}$ per $\mathrm{mmHg}$ ) was estimated from SAP and RR by means of the sequence method (Bertinieri et al. 1988). In practice, we selected intermittent short sequences of 


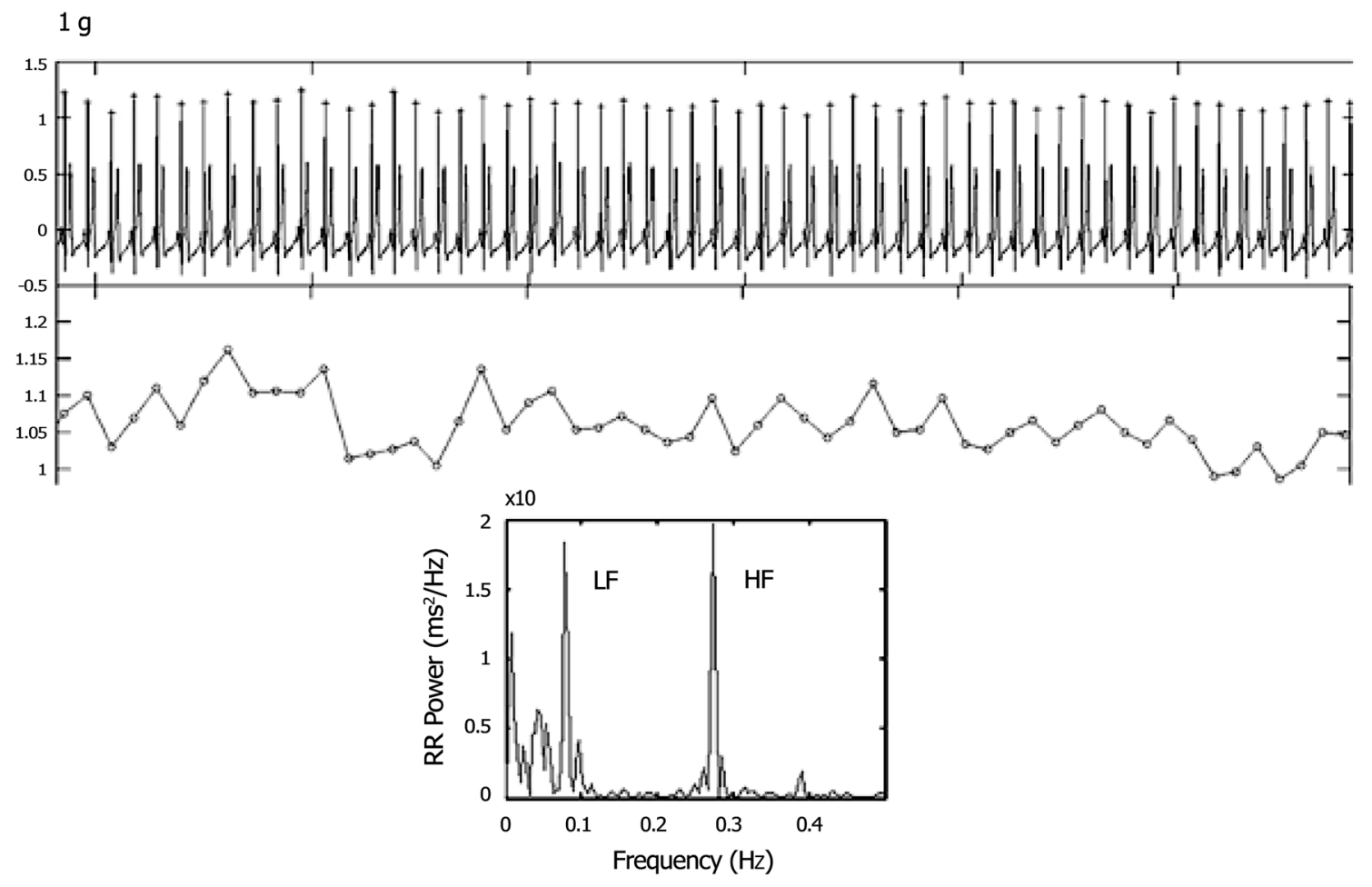

$2.5 \mathrm{~g}$
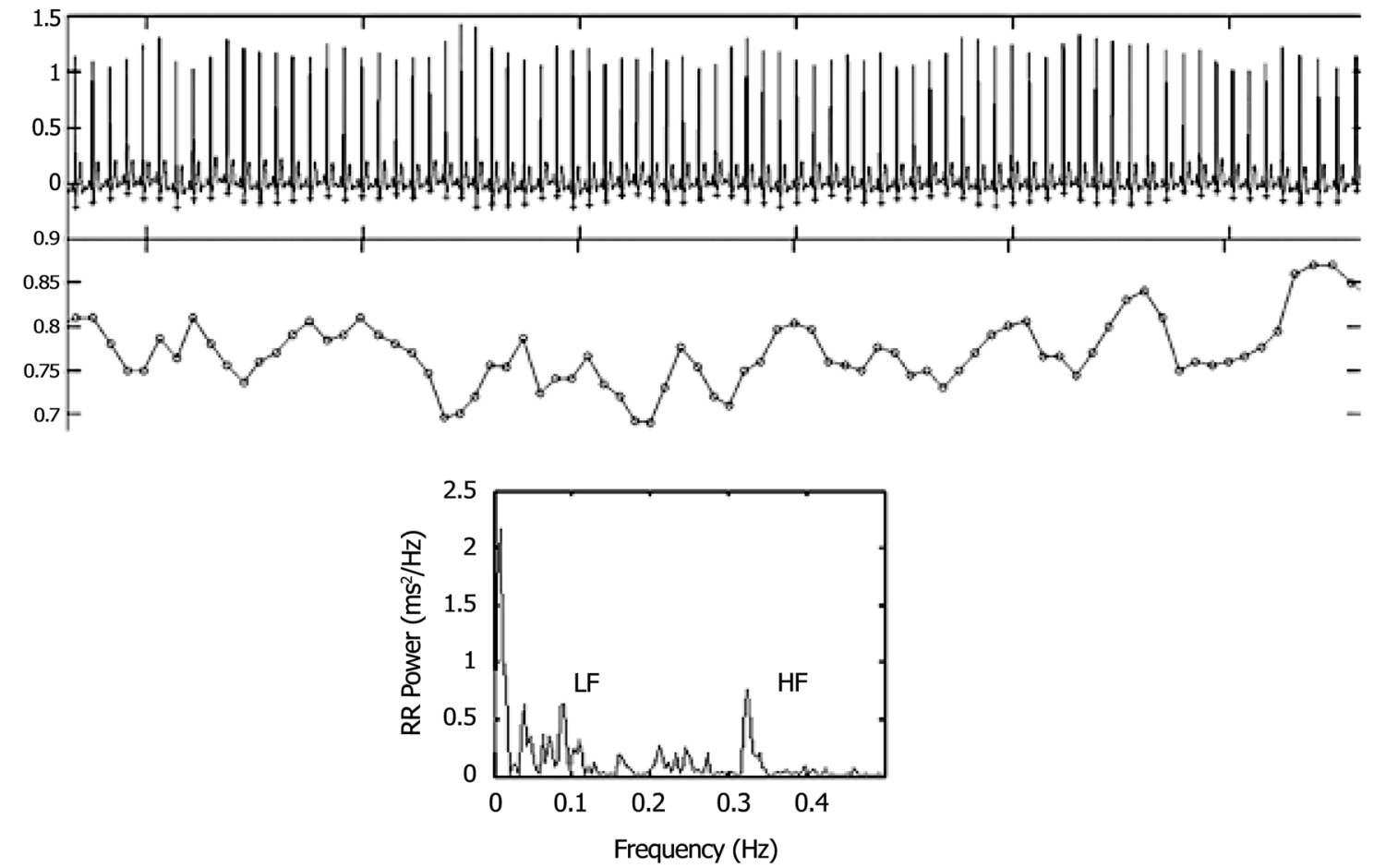

Fig. 2 Examples of a segment of ECG recording, with the corresponding RR time series, and the heart rate variability spectrum resulting from the experiment which the shown ECG segment belongs to top $1 \mathrm{~g}$, bottom $2.5 \mathrm{~g}$ 


\section{$1 \mathrm{~g}$}
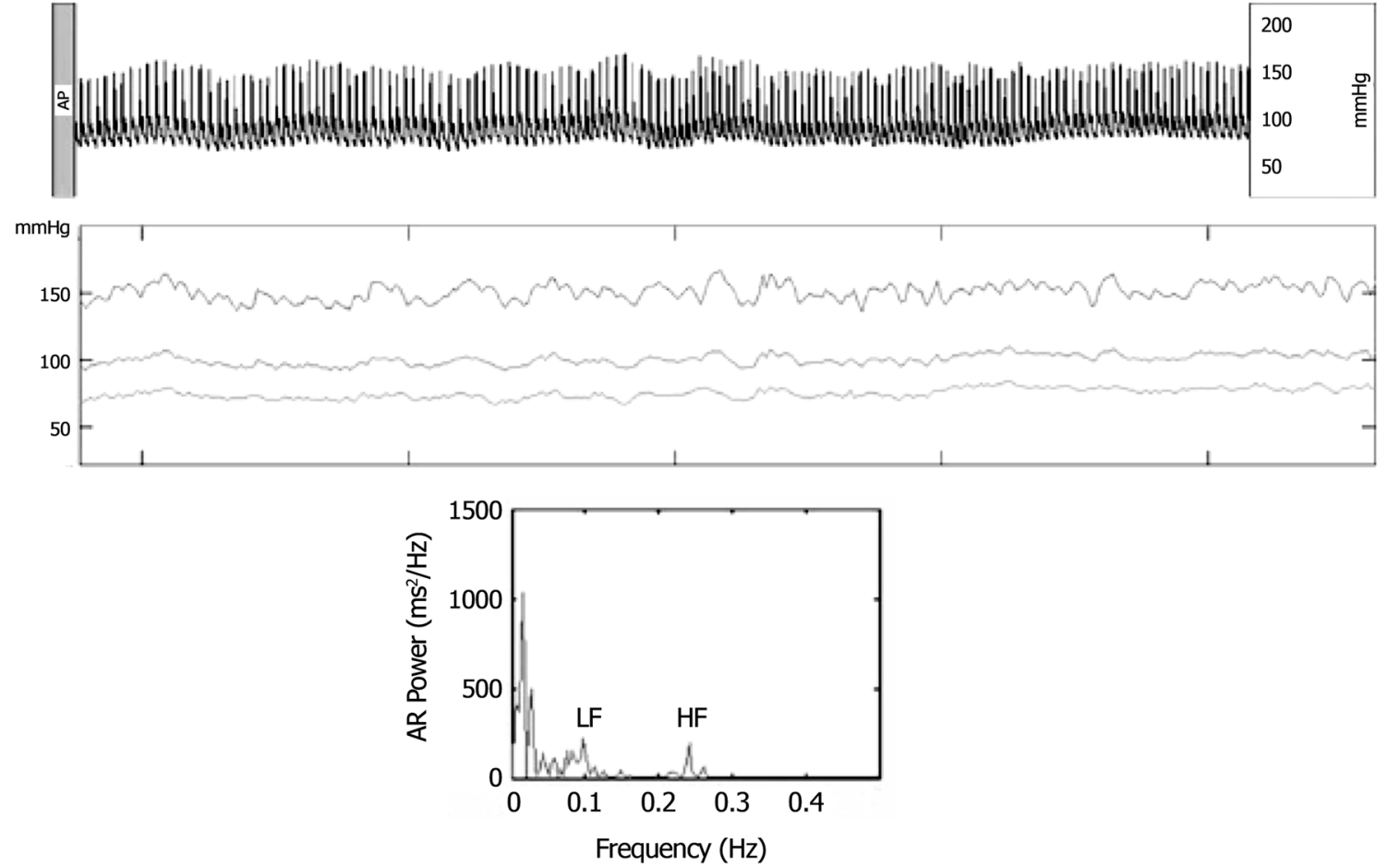

\section{$2.5 \mathrm{~g}$}

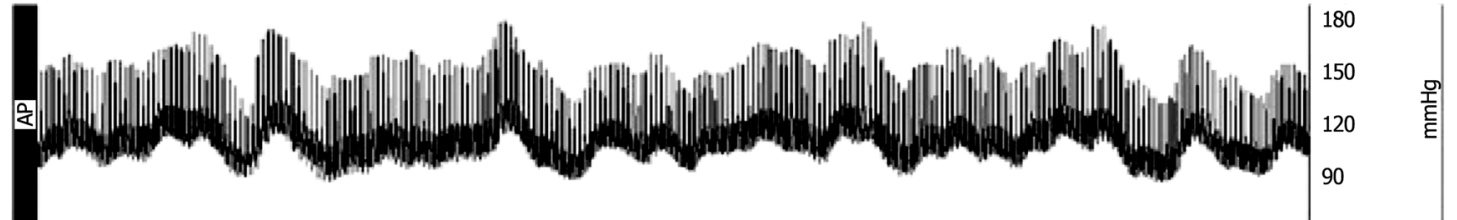

$\mathrm{mmHg}$
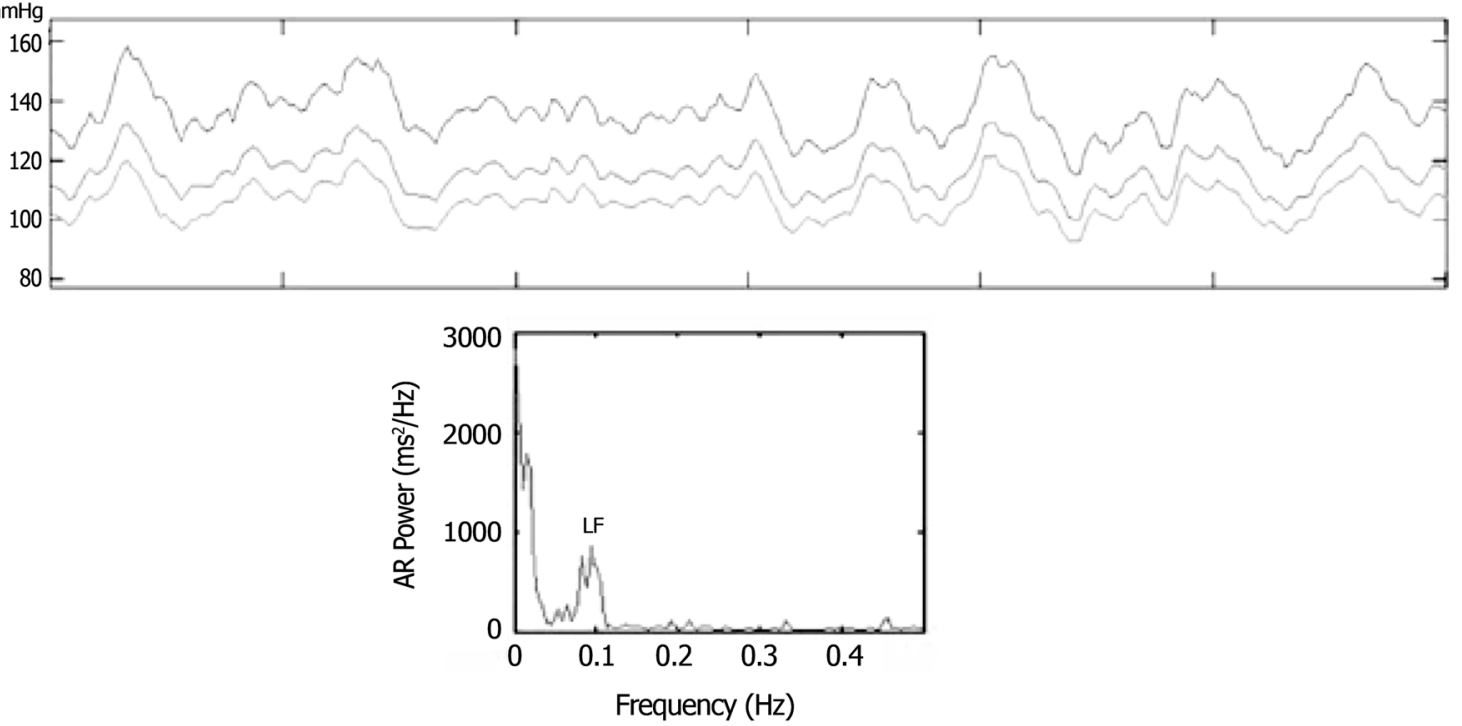

Fig. 3 Examples of a segment of arterial pressure recording, with the corresponding temporal series with SAP, MAP and DAP, and the SAP variability spectrum resulting from the experiment which the shown arterial pressure segment belongs to top $1 \mathrm{~g}$, bottom $2.5 \mathrm{~g}$ 
Table 1 Mean values measured at steady state and at each level of gravity acceleration $\left(a_{\mathrm{g}}\right)$

\begin{tabular}{lcccc}
\hline Measured variables & $1 \mathrm{G}$ & $1.5 \mathrm{G}$ & $2 \mathrm{G}$ & $2.5 \mathrm{G}$ \\
\hline HR $(\mathrm{bpm})$ & $70.20 \pm 9.10$ & $79.52 \pm 6.19^{*}$ & $90.22 \pm 13.64^{*}$ & $102.58 \pm 15.25^{*}$ \\
SAP $(\mathrm{mmHg})$ & $132.19 \pm 12.46$ & $127.98 \pm 25.75$ & $127.87 \pm 16.41$ & $132.59 \pm 14.39$ \\
DAP $(\mathrm{mmHg})$ & $68.73 \pm 7.01$ & $75.03 \pm 11.51$ & $76.59 \pm 10.87$ & $82.04 \pm 12.55^{*}$ \\
MAP (mmHg) & $89.88 \pm 8.12$ & $92.67 \pm 15.62$ & $93.69 \pm 12.05$ & $98.88 \pm 12.05^{*}$ \\
\hline
\end{tabular}

Data are given as means and standard deviations of all measured variables at steady state at each level of $a_{\mathrm{g}}$ $H R$ heart rate, SAP systolic arterial pressure, DAP diastolic arterial pressure, MAP mean arterial pressure

* Significantly different from $1 \mathrm{G}$

Table 2 Means and standard deviations of all calculated variables at steady state at each level of gravitational acceleration $\left(a_{\mathrm{g}}\right)$

\begin{tabular}{lcccc}
\hline Measured variables & $1 \mathrm{G}$ & $1.5 \mathrm{G}$ & $2 \mathrm{G}$ & $2.5 \mathrm{G}$ \\
\hline $\mathrm{RR}(\mathrm{ms})$ & $870.34 \pm 114.29$ & $762.88 \pm 59.03^{*}$ & $680.04 \pm 89.74 *$ & $598.75 \pm 89.49 *$ \\
$f_{\mathrm{LF}} \mathrm{RR}(\mathrm{Hz})$ & $0.096 \pm 0.015$ & $0.099 \pm 0.014$ & $0.094 \pm 0.023$ & $0.088 \pm 0.015$ \\
$f_{\mathrm{HF}} \mathrm{RR}(\mathrm{Hz})$ & $0.294 \pm 0.049$ & $0.325 \pm 0.057$ & $0.302 \pm 0.069$ & $0.335 \pm 0.090$ \\
$\mathrm{BRS}\left(\mathrm{ms} \mathrm{mmHg}^{-1}\right)$ & $11.57 \pm 2.85$ & $9.95 \pm 6.19$ & $7.46 \pm 6.48^{*}$ & $4.88 \pm 2.15 *$ \\
\hline
\end{tabular}

Data are given as means and standard deviations of all calculated variables at steady state at each level of $a_{\mathrm{g}}$

$R R$ R-R interval, $f_{L F} R R(H z)$ central frequency of the LF component of heart rate variability, $f_{H F} R R(H z)$ central frequency of the LF component of heart rate variability, $B R S$ Spontaneous baroreflex sensitivity

* Significantly different from $1 \mathrm{G}$

at least three heart beats during which SAP increased or decreased resulting in a change in RR interval going to the same direction, resulting from a cardiovascular reflex. The software calculated the linear regression slope for each sequence, and only those sequences in which the value of $r^{2}$ was more than 0.85 were accepted and the slope retained. Then, BRS was calculated as the mean of the slopes of all sequences of each subject.

Spectral analysis and spontaneous baroreflex sensitivity were both analysed by means of BRSanalysis, a purposely laboratory-made programme written with Matlab ${ }^{\circledR}$ software (Version 7.9.1 R2009b) and produced by the Autonomic Nervous System Team at the University Jean-Monnet, Saint-Etienne, France (Assoumou et al. 2012; Costes et al. 2004; Dauphinot et al. 2013).

\section{Statistical analysis}

Data are reported as mean \pm standard deviation for each experimental session. The effects of $a_{\mathrm{g}}$ on the investigated parameters were analysed by 2-way ANOVA for repeated measurements. Then, Tukey Post-hoc test has been applied to identify corresponding samples. $a_{\mathrm{g}}$ was fitted as parametric variable. All data were analysed with Statview 5@. (SAS Institute Inc., Cary, NC, USA) The results were considered significant if $p<0.05$

\section{Results}

The mean values measured at steady state at each level of $a_{\mathrm{g}}$ are shown in Table 1. HR at $2.5 \mathrm{~g}$ was $47.1 \pm 20.7 \%$ higher than that at $1 \mathrm{~g}$. Consistently, RR at $2.5 \mathrm{~g}$ was $30.76 \pm 9.46 \%$ lower than that at $1 \mathrm{~g}$. No arrhythmic beats were observed, and in all cases a normal sinus beat was maintained. Differences were significant between each $a_{\mathrm{g}}$ level. SAP did not change with $a_{\mathrm{g}}$, whereas DAP increased, being at $2.5 \mathrm{~g}$ significantly higher than that at $1 \mathrm{~g}(+19.5 \pm 14.6 \%)$. Consistently, MAP at $2.5 \mathrm{~g}$ was also significantly higher than that at $1 \mathrm{~g}(+10.2 \pm 10.81 \%)$.

The mean values calculated at steady state at each level of $a_{\mathrm{g}}$ are shown in Table 2. The central frequency of the $\mathrm{HF}$ component of RR, that is known to well represent the breathing frequency, did not change significantly with $a_{\mathrm{g}}$. The same was the case for the central frequency of the LF component of RR. At $2.5 \mathrm{~g}$, the BRS decrease attained $57.4 \pm 17.7 \%$. This progressive BRS decrease led to significant changes at 2 and $2.5 \mathrm{~g}$ as compared to $1 \mathrm{~g}$. The BRS at $2.5 \mathrm{~g}$ was also significantly lower than that at $1.5 \mathrm{~g}$.

Means and standard deviations of all data calculated by means of HRV spectral analysis are shown in Table 3. $P_{\text {TOT }}$ decreased progressively with increasing $a_{\mathrm{g}}$ from $1 \mathrm{~g}$ to $2.5 \mathrm{~g}$. The $P_{\text {TOT }}$ value at $2.5 \mathrm{~g}$ was significantly lower than the corresponding values at 1 and $1.5 \mathrm{~g}$. Although the LF 
Table 3 Means and standard deviations of all parameters calculated by means of heart rate variability, systolic arterial pressure and diastolic arterial pressure

\begin{tabular}{|c|c|c|c|c|}
\hline & $1 \mathrm{G}$ & $1.5 \mathrm{G}$ & $2 \mathrm{G}$ & $2.5 \mathrm{G}$ \\
\hline \multicolumn{5}{|l|}{ HRV } \\
\hline$P_{\mathrm{TOT}}\left(\mathrm{ms}^{2} \mathrm{~Hz}^{-1}\right)$ & $1984.1 \pm 390.6$ & $1745.0 \pm 411.2$ & $1421.9 \pm 432.4$ & $657.0 \pm 157.8^{* \#}$ \\
\hline $\mathrm{LF}\left(\mathrm{ms}^{2} \mathrm{~Hz}^{-1}\right)$ & $702.9 \pm 147.4$ & $744.7 \pm 190.7$ & $640.8 \pm 213.9$ & $336.8 \pm 105.4^{\#}$ \\
\hline $\mathrm{HF}\left(\mathrm{ms}^{2} \mathrm{~Hz}^{-1}\right)$ & $314.4 \pm 57.4$ & $289.0 \pm 115.7$ & $186.9 \pm 68.9$ & $66.7 \pm 15.4^{* \#}$ \\
\hline $\mathrm{LF} / \mathrm{HF}$ & $2.60 \pm 0.38$ & $3.84 \pm 0.55$ & $4.41 \pm 0.91$ & $4.97 \pm 1.34 *$ \\
\hline LFnu (\%) & $64.95 \pm 3.42$ & $73.35 \pm 2.82$ & $72.36 \pm 4.18$ & $69.17 \pm 5.11$ \\
\hline HFnu (\%) & $34.91 \pm 3.42$ & $26.21 \pm 2.75$ & $24.87 \pm 3.42$ & $24.34 \pm 3.47$ \\
\hline \multicolumn{5}{|l|}{ SAP } \\
\hline$P_{\mathrm{TOT}}\left(\mathrm{ms}^{2} \mathrm{~Hz}^{-1}\right)$ & $24.77 \pm 3.94$ & $33.77 \pm 3.71$ & $44.23 \pm 4.87 *$ & $46.63 \pm 5.81^{*}$ \\
\hline $\mathrm{LF}\left(\mathrm{ms}^{2} \mathrm{~Hz}^{-1}\right)$ & $9.04 \pm 1.61$ & $11.38 \pm 2.17$ & $19.37 \pm 3.96^{*}$ & $24.18 \pm 5.02^{* \#}$ \\
\hline $\mathrm{HF}\left(\mathrm{ms}^{2} \mathrm{~Hz}^{-1}\right)$ & $2.80 \pm 0.47$ & $5.04 \pm 1.18$ & $7.83 \pm 1.28 *$ & $8.24 \pm 1.73 *$ \\
\hline $\mathrm{LF} / \mathrm{HF}$ & $4.99 \pm 1.29$ & $3.04 \pm 0.40$ & $3.28 \pm 0.75$ & $4.51 \pm 1.00$ \\
\hline \multicolumn{5}{|l|}{ DAP } \\
\hline$P_{\mathrm{TOT}}\left(\mathrm{ms}^{2} \mathrm{~Hz}^{-1}\right)$ & $8.17 \pm 1.28$ & $11.76 \pm 2.01$ & $15.73 \pm 2.59$ & $20.53 \pm 3.23^{* \#}$ \\
\hline $\mathrm{LF}\left(\mathrm{ms}^{2} \mathrm{~Hz}^{-1}\right)$ & $3.41 \pm 0.46$ & $5.01 \pm 1.05$ & $8.15 \pm 1.69$ & $11.9 \pm 2.33^{* \#}$ \\
\hline $\mathrm{HF}\left(\mathrm{ms}^{2} \mathrm{~Hz}^{-1}\right)$ & $1.25 \pm 0.76$ & $1.85 \pm 0.86$ & $2.69 \pm 0.76$ & $3.02 \pm 0.64$ \\
\hline $\mathrm{LF} / \mathrm{HF}$ & $9.45 \pm 1.39$ & $6.22 \pm 0.95 *$ & $5.17 \pm 1.06^{*}$ & $7.67 \pm 1.2$ \\
\hline
\end{tabular}

Data are given as means and standard deviations of all parameters calculated at steady state at each level of $a_{\mathrm{g}}$

$H R V$ heart rate variability, $S A P$ systolic arterial pressure, $D A P$ diastolic arterial pressure, $P_{T O T}$ total power, $L F$ low frequency, $H F$ high frequency, $L F / H F$ low and high frequency ratio

* Significantly different from $1 \mathrm{~g}$

\# Significantly different from $1.5 \mathrm{~g}$

power at $1 \mathrm{~g}$ did not change with increasing $a_{\mathrm{g}}$ up to $2 \mathrm{~g}$, the value at $2.5 \mathrm{~g}$ resulted remarkably reduced. This change was significantly different with respect to the value at $1.5 \mathrm{~g}$. HF power decreased progressively and significantly with increasing $a_{\mathrm{g}}$, from 1 to $2.5 \mathrm{~g}$. This last value was significantly lower than the corresponding values at 1 and $1.5 \mathrm{~g}$. The LF/HF ratio thus increased significantly between 1 and $2.5 \mathrm{~g}$, growing by $105.8 \pm 156.1 \%$. LFnu and HFnu did not change significantly with $a_{\mathrm{g}}$.

Means and standard deviations of all data calculated by means of SAP spectral analysis are shown in Table 3. $P_{\text {TOT }}$ increased progressively and significantly from 1 to $2.5 \mathrm{~g}$. The value at $2.5 \mathrm{~g}$ represented a $127.8 \pm 132.9 \%$ increase with respect to the corresponding value at $1 \mathrm{~g}$ and was significantly higher than the corresponding value at $1 \mathrm{~g}$. The same was the case for the value at $2 \mathrm{~g}$. LF power increased progressively with increasing $a_{\mathrm{g}}$, to reach the maximum at $2.5 \mathrm{~g}$. At this $a_{\mathrm{g}}$ level, LF power was $232.5 \pm 257.3 \%$ higher than that at $1 \mathrm{~g}$ and significantly different from that observed at 1 and $1.5 \mathrm{~g}$. Also the value at $2 \mathrm{~g}$ was significantly higher than the corresponding value at $1 \mathrm{G}$. HF power increased progressively with increasing $a_{\mathrm{g}}$. Value at $2.5 \mathrm{~g}$ was $248.9 \pm 230.5 \%$ higher than that at $1 \mathrm{~g}$. Values at 2 and $2.5 \mathrm{~g}$ were significantly higher than the corresponding value at $1 \mathrm{~g}$. The $\mathrm{LF} / \mathrm{HF}$ ratio, as well as LFnu and HFnu, did not change significantly with increasing $a_{\mathrm{g}}$.

Means and standard deviations of all data calculated by means of DAP spectral analysis are shown in Table 3. $P_{\text {TOT }}$ increased progressively and significantly with increasing $a_{\mathrm{g}}$ until $2.5 \mathrm{~g}$. This last value was $190.6 \pm 146.6 \%$ higher than and significantly different from the corresponding value at $1 \mathrm{~g}$. It was also significantly higher than the value at $1.5 \mathrm{~g}$. The value at $2 \mathrm{~g}$ was significantly higher than that at $1 \mathrm{~g}$. LF power increased progressively with increasing $a_{\mathrm{g}}$ and significantly at 2 and $2.5 \mathrm{~g}$. This represented a $275 \pm 224.8 \%$ increase. HF power did not change significantly between $1 \mathrm{~g}$ and $2.5 \mathrm{~g}$. LF/HF ratio decreased progressively and significantly until $2 \mathrm{~g}$. The rebound observed at $2.5 \mathrm{~g}$ was such as to have no significant differences with respect to any other $a_{\mathrm{g}}$ level. LFnu and HFnu did not change significantly with $a_{\mathrm{g}}$.

\section{Discussion}

The absolute steady-state values of the measured variables conformed with previous observations (Bjurstedt et al. 1968; Bonjour et al. 2011; Burton and Smith 2011; 
Pendergast et al. 2012; Rosenhamer 1967): as $a_{\mathrm{g}}$ was increased, HR and DAP grew and SAP did not change, which implied an increase in MAP. On the same subjects, in a previous study (Bonjour et al. 2011), a decrease in cardiac output and stroke volume as a function of $a_{\mathrm{g}}$ was found. The increase in DAP can be attributed to an increase in $R_{\mathrm{p}}$, also reported by Bonjour et al. (2011), as a consequence of arteriolar vasoconstriction, possibly due to sympathetic stimulation of alpha-adrenergic receptors (Inagaki et al. 2011). We propose that the drop of venous return, as suggested by low stroke volume and cardiac output, induced a switch toward sympathetic up-regulation of the cardiovascular system at rest, leading to higher $R_{\mathrm{p}}$ and MAP (vascular regulation) and to higher HR (cardiac regulation). It was therefore logical to expect that HRV indexes in condition of high $a_{\mathrm{g}}$ change in the direction of sympathetic up-regulation.

We thus analysed for the first time the spontaneous variability of RR, SAP and DAP in hypergravity condition by means of power spectral analysis. The choice of FFT relied on two considerations: on one side, the implicit assumptions underlying the application of autoregressive methods are unwarranted at elevated $a_{\mathrm{g}}$ levels; on the other side, our study was carried out in steady-state conditions (Bonjour et al. 2011) and FFT is considered accurate when it is used during steady states (Task force of the European Society of Cardiology and the North American Society of Pacing and Electrophysiology 1996). We also comment a posteriori that the present results have shown a reduction of the total power with increasing $a_{\mathrm{g}}$, a condition in which FFT was demonstrated to be a most reliable technique (Weippert et al. 2010). We nevertheless acknowledge that application of autoregressive analysis would have in principle allowed a more consistent and smoother spectral estimation, a spectral resolution independent of the number of samples and the possibility of avoiding windowing procedures (Pagani et al. 1986). Moreover, autoregressive models would have allowed decomposition of the autocorrelation function in single components, thus directly providing the individual centre frequency, which in this case had to be recalculated off-line.

The most common condition implying up-regulation of the sympathetic system is exercise. Already, the classical study of Robinson et al. (1966) demonstrated a progressively greater sympathetic activity as the power at which exercise was carried out increased. Moreover, a reduction of $P_{\text {TOT }}$ of HRV typically occurs when only one branch of the ANS is active, as is the case during exercise. As soon as exercise starts, there is an immediate HR increase, which was attributed to sudden withdrawal of vagal regulation (Arai et al. 1989; Fagraeus and Linnarsson 1976; Lador et al. 2006; Perini et al. 1990). At $30 \%$ of the maximal power, most of the decrease in $P_{\text {TOT }}$ known to occur during exercise has already taken place (Perini et al. 1990). The reduction of $P_{\text {TOT }}$ that we found in hypergravity is thus in agreement with what is currently observed in exercise (Perini et al. 1990; Perini and Veicsteinas 2003). During exercise, there is also an increase of the power of the LF component of SAP variability (Perini and Veicsteinas 2003; Cottin et al. 2008), a finding that characterises also the present results and is coherent with the concept of an increased peripheral sympathetic activity. There is however a remarkable difference between exercise and hypergravity, namely that in the former case the up-regulation of the sympathetic system occurs at low $R_{\mathrm{p}}$, while in the latter it occurs at elevated $R_{\mathrm{p}}$. This entails differences in the peripheral (vascular) component of oscillatory regulation mechanisms. In fact, an exercising human undergoes a major increase in muscle blood flow with respect to rest, with consequent dramatic fall of $R_{\mathrm{p}}$ (Ferretti et al. 1995; Rådegran and Saltin 1998), whereas hypergravity at rest is characterised by strong peripheral vasoconstriction (Bonjour et al. 2011; Linnarsson and Rosenhamer 1968).

Respiratory rate is also a major difference between hypergravity and exercise. Previous work done with the same set-up and subjects showed that there were no significant changes of resting ventilation with increased $a_{\mathrm{g}}$ (Bonjour et al. 2011). Coherently, neither the power of the HF component of HRV nor its central frequency varied with increasing $a_{\mathrm{g}}$. This is obviously not the case with exercise. Respiratory rate is well known to modulate HF component of HRV (Perini and Veicsteinas 2003), the power of which increases at exercise intensities above the so-called ventilatory threshold (Cottin et al. 2008). Other conditions characterised by reduced $P_{\text {TOT }}$ of HRV are exposure to acute hypoxia (Brown et al. 2013; Buchheit et al. 2004) and chronic heart failure (Lombardi and Mortara 1998; Rydlewska et al. 2011). Also, these conditions, however, entail physiological differences with respect to hypergravity, as far as cardiac output is concerned.

In this study, the reduction of the HF component of $\mathrm{HRV}$, at least at 2 and $2.5 \mathrm{~g}$, was associated with a smaller decrease in LF. As a consequence, (1) $P_{\mathrm{TOT}}$, decreased significantly; and (2) the LF/HF ratio increased significantly. However, an increase of the LF/HF ratio should imply significant increases in LFnu and decreases in HFnu. This was not the case, although a tendency toward a decrease is evident for HFnu. These results reveal dissociation between oscillatory (HRV parameters) and tonic (steady-state physiological variables) indices of cardiovascular regulation, as long as the latter, but not the former, are varied at elevated $a_{\mathrm{g}}$ levels (Bonjour et al. 2011). A similar dissociation was observed also after prolonged bed rest (Ferretti et al. 2009) and was related to the different meaning of these indices. The occurrence of changes in LFnu and HFnu is a crucial issue for the evaluation of the sympatho-vagal balance 
concept (Pagani and Malliani 2000). These results rather suggest that the sympatho-vagal balance is not a key issue under elevated $a_{\mathrm{g}}$ conditions, considering also that in the present study the control condition was sitting instead of supine, in which case LFnu is already elevated.

In order to clarify the origin of the LF decrease for HRV, we analysed the spontaneous variability of SAP and DAP. Contrary to the LF component of HRV, the LF powers of both SAP and DAP increased progressively and significantly with increasing $a_{\mathrm{g}}$, whereas the corresponding HF powers also significantly increased. This revealed the dissociation between the peripheral (arterial pressure control) and the cardiac (HRV) oscillatory components under the present circumstances. The increase in LF is coherent with the hypothesis that LF may have some links with the peripheral sympathetic activity (Pagani et al. 1997). Peripheral sympathetic activity can be investigated by analysing the muscle sympathetic nerve activity (MSNA). MSNA is increased in exercise (Victor et al. 1995) and head-down bed rest (Tanaka et al. 2013), all conditions that are generally associated with an increase in SAP LF power. Unfortunately, measuring MSNA was an impossible task in a spinning gondola due to space limitation and the exerted forces. The only data we are aware of, supporting these notions, were obtained during centrifugation at $3 g$ and showed that both adrenaline and noradrenaline were increased (Schneider et al. 2008).

Mean BRS at $1 \mathrm{~g}$ was similar to the values reported with the same method in previous studies (Kardos et al. 2001). As long as $a_{\mathrm{g}}$ was increased, BRS decreased progressively and significantly. When MAP is artificially increased, e.g. by means of a bolus of phenylephrine (La Rovere et al. 2008), the ensuing MAP correction by arterial baroreflexes is mediated by increased cardiac parasympathetic outflow to the sinoatrial node. In a condition where the vagal branch of the ANS is inhibited, one would expect an impairment of such a MAP correction, as evidenced by a decrease in BRS. The hydrostatic force that is generated, e.g. by doubling $a_{\mathrm{g}}$, unloads carotid baroreceptors remarkably - the exact amount depends in fact also on the position of the indifferent hydrostatic point in hypergravity, which is unknown in the present subjectsso that the subjects may move toward the functional limits of arterial baroreflexes, a fact which per se would imply an acute reduction of BRS. In fact, age, among many factors, is known to be a major determinant of BRS impairment (Kardos et al. 2001; Laitinen et al. 1998; Piccirillo et al. 2001). Lower BRS values than the present ones were found on older subjects than the present subjects (Parati et al. 1988; Tank et al. 2000). Similar effects on BRS were found also during head-up-tilt after $6 \mathrm{~h}$ of water immersion (Florian et al. 2013) or at the end of prolonged headdown bed rest (Ferretti et al. 2009; Sigaudo et al. 1998).
All these conditions entail an increased sympathetic regulation (Kamiya et al. 1999; O'Leary et al. 2003). The low BRS values represent an intriguing aspect of this study, as long as they are associated with higher LF values and elevated DAP values. In more general terms, the reduction of BRS in association with an increased vascular regulation response reveals the complexity of the autonomic regulation in conditions of acute $a_{\mathrm{g}}$ elevation, which would require joint perusal of several indices simultaneously.

\section{Conclusion}

The decrease in the power of the LF component of HRV, as well as in $P_{\mathrm{TOT}}$, was associated, on one side, with a lack of significant changes in LFnu and HFnu and, on the other side, with significant changes in the LF/HF ratio. These results do not agree with the notion of sympathetic up-regulation, suggested by the increase in HR and DAP (tonic indices) and the increase in both SAP and DAP LF powers (oscillatory indices). Yet the $P_{\text {TOT }}$ reduction leads us to speculate that only the sympathetic branch of the ANS might have been active during elevated $a_{\mathrm{g}}$ exposure. The finding that the vascular response, as revealed by the higher LF power of arterial pressure variability, occurred in a condition of massive baroreceptive unloading may indicate new tracks for the study of vascular regulation and, possibly, vascular to central interactions.

Acknowledgments This study was supported by Swiss National Science Foundation grants 3200B0 102181 and 32003B_143427 to Guido Ferretti, by a grant from the Access to Ground Based Facilities Initiative of the European Space Agency to Dag Linnarsson and by Italian Space Agency grant ASI/DCMC to Carlo Capelli.

\section{References}

Arai Y, Saul JP, Albrecht P, Hartley LH, Lilly LS, Cohen RJ, Colucci WS (1989) Modulation of cardiac autonomic activity during and immediately after exercise. Am J Physiol Heart Circ Physiol 256:H132-H141

Arbeille P, Kerbeci P, Mattar L, Shoemaker JK, Hughson R (2008) Insufficient flow reduction during LBNP in both splanchnic and lower limb areas is associated with orthostatic intolerance after bedrest. Am J Physiol Heart Circ Physiol 295:H1846-H1854

Assoumou H-GN, Bertholon F, Barthélémy J-C, Pichot V, Celle S, Gosse P, Gaspoz J-M, Roche F (2012) Alteration of baroreflex sensitivity in the elderly: the relationship with metabolic syndrome components. Int J Cardiol 155:333-335

Azabji-Kenfack M, Lador F, Licker M, Moia C, Tam E, Capelli C, Morel D, Ferretti G (2004) Cardiac output by Modelflow method from intra-arterial and fingertip pulse pressure profiles. Clin Sci 106:365-369

Barbe P, Galitzky J, Thalamas C, Langin D, Lafontan M, Senard JM, Berlan M (1999) Increase in epinephrine-induced responsiveness during microgravity simulated by head-down bed rest in humans. J Appl Physiol 87:1614-1620 
Bertinieri G, Di Rienzo M, Cavallazzi A, Ferrari AU, Pedotti A, Mancia G (1988) Evaluation of baroreceptor reflex by blood pressure monitoring in unanesthetized cats. Am J Physiol Heart Circ Physiol 254:H377-H383

Bjurstedt H, Rosenhamer G, Wigertz O (1968) High-g environment and responses to graded exercise. J Appl Physiol 25:713-719

Bjurstedt H, Rosenhamer G, Tydén G (1974) Acceleration stress and effects of propranolol on cardiovascular responses. Acta Physiol Scand 90:491-500

Bonjour J, Capelli C, Antonutto G, Calza S, Tam E, Linnarsson D, Ferretti G (2010) Determinants of oxygen consumption during exercise on cycle ergometer: The effects of gravity acceleration. Respir Physiol Neurophysiol 171:128-134

Bonjour J, Bringard A, Antonutto G, Capelli C, Linnarsson D, Pendergast DR, Ferretti G (2011) Effects of acceleration in the $G_{z}$ axis on human cardiopulmonary responses to exercise. Eur J Appl Physiol 111:2907-2917

Brown SJ, Raman A, Barnes MJ, Mündel T (2013) Autonomic cardiovascular response to acute hypoxia and passive head-up tilting in humans. Eur J Appl Physiol 113:1731-1736

Buchheit M, Richard R, Doutreleau S, Lonsdorfer-Wolf E, Brandenberger G, Simon C (2004) Effect of acute hypoxia on heart rate variability at rest and during exercise. Int $\mathbf{J}$ Sports Med 25:264-269

Burton RR, Smith AH (2011) Adaptation to Acceleration Environments. Compr Physiol Suppl 14:943-970

Christensen NJ, Heer M, Ivanova K, Norsk P (2005) Sympathetic nervous activity decreases during head-down bed rest but not during microgravity. J Appl Physiol 99:1552-1557

Costes F, Roche F, Pichot V, Vergnon JM, Garet M, Barthelemy JC (2004) Influence of exercise training on cardiac baroreflex sensitivity in patients with COPD. Eur Respir J 23:396-401

Cottin F, Médigue C, Papelier Y (2008) Effect of heavy exercise on spectral baroreflex sensitivity, heart rate, and blood pressure variability in well-trained humans. Am J Physiol Heart Circ Physiol 295:H1150-H1155

Dauphinot V, Kossovsky MP, Gueyffier F, Pichot V, Gosse P, Roche F, Barthélémy J-C (2013) Impaired baroreflex sensitivity and the risks of new-onset ambulatory hypertension, in an elderly population-based study. Int J Cardiol 168:4010-4014

Drouin E, Gournay V, Calamel J, Mouzard A, Rozé JC (1997) Assessment of spontaneous baroreflex sensitivity in neonates. Arch Dis Child Fetal Neonatal Ed 76:F108-F112

Eckberg DL, Neurolab Autonomic Nervous System Team (2003) Bursting into space: alterations of sympathetic control by space travel. Acta Physiol Scand 177:299-311

Edgell H, Zuj KA, Greaves DK, Shoemaker JK, Custaud M-A, Kerbeci P, Arbeille P, Hughson RL (2007) WISE-2005: adrenergic responses of women following 56-days, 6 degrees head-down bed rest with or without exercise countermeasures. Am J Physiol Regul Integr Comp Physiol 293:R2343-R2352

Ertl AC, Diedrich A, Biaggioni I, Levine BD, Robertson RM, Cox JF, Zuckerman JH, Pawelczyk JA, Ray CA, Buckey JC Jr, Lane LD, Shiavi R, Gaffney FA, Costa F, Holt C, Blomqvist CG, Eckberg DL, Baisch FJ, Robertson D (2002) Human muscle sympathetic nerve activity and plasma noradrenaline kinetics in space. J Physiol (Lond) 538:321-329

Fagraeus L, Linnarsson D (1976) Autonomic origin of heart rate fluctuations at the onset of muscular exercise. J Appl Physiol 40:679-682

Ferretti G, Binzoni T, Hulo N, Kayser B, Thomet JM, Cerretelli P (1995) Kinetics of oxygen consumption during maximal exercise at different muscle temperatures. Respir Physiol 102:261-268

Ferretti G, Iellamo F, Pizzinelli P, Kenfack MA, Lador F, Lucini D, Porta A, Narkiewicz K, Pagani M (2009) Prolonged head down bed rest-induced inactivity impairs tonic autonomic regulation while sparing oscillatory cardiovascular rhythms in healthy humans. J Hypertens 27:551-561

Florian JP, Simmons EE, Chon KH, Faes L, Shykoff BE (2013) Cardiovascular and autonomic responses to physiological stressors before and after $6 \mathrm{~h}$ of water immersion. J Appl Physiol 115:1275-1289

Fortrat JO, Sigaudo D, Hughson RL, Maillet A, Yamamoto Y, Gharib C (2001) Effect of prolonged head-down bed rest on complex cardiovascular dynamics. Auton Neurosci 86:192-201

Girardis M, Linnarsson D, Moia C, Pendergast DR, Ferretti G (1999) Oxygen cost of dynamic leg exercise on a cycle ergometer: effects of gravity acceleration. Acta Physiol Scand 166:239-246

Hirayanagi K, Iwase S, Kamiya A, Sasaki T, Mano T, Yajima K (2004) Functional changes in autonomic nervous system and baroreceptor reflex induced by 14 days of 6 degrees head-down bed rest. Eur J Appl Physiol 92:160-167

Hughson RL, Maillet A, Gauquelin G, Arbeille P, Yamamoto Y, Gharib C (1995) Investigation of hormonal effects during 10-h head-down tilt on heart rate and blood pressure variability. J Appl Physiol 78:583-596

Inagaki T, Sonobe T, Poole DC, Kano Y (2011) Progressive arteriolar vasoconstriction and fatigue during tetanic contractions of rat skeletal muscle are inhibited by $\alpha$-receptor blockade. J Physiol Sci 61:181-189

Kamiya A, Iwase S, Kitazawa H, Mano T (1999) Muscle sympathetic nerve activity (MSNA) after 120 days of 6 degrees head-down bed rest (HDBR). Environ Med 43:150-152

Kamiya A, Michikami D, Iwase S, Hayano J, Kawada T, Sugimachi M, Sunagawa K (2004) Alpha-adrenergic vascular responsiveness to sympathetic nerve activity is intact after head-down bed rest in humans. Am J Physiol Regul Integr Comp Physiol 286:R151-R157

Kardos A, Watterich G, de Menezes R, Csanády M, Casadei B, Rudas L (2001) Determinants of spontaneous baroreflex sensitivity in a healthy working population. Hypertension 37:911-916

La Rovere MT, Pinna GD, Raczak G (2008) Baroreflex sensitivity: measurement and clinical implications. Ann Noninvasive Electrocardiol 13:191-207

Lador F, Azabji Kenfack M, Moia C, Cautero M, Morel DR, Capelli C, Ferretti G (2006) Simultaneous determination of the kinetics of cardiac output, systemic $\mathrm{O}(2)$ delivery, and lung $\mathrm{O}(2)$ uptake at exercise onset in men. Am J Physiol Regul Integr Comp Physiol 290:R1071-R1079

Laitinen T, Hartikainen J, Vanninen E, Niskanen L, Geelen G, Länsimies E (1998) Age and gender dependency of baroreflex sensitivity in healthy subjects. J Appl Physiol 84:576-583

Linnarsson D, Rosenhamer G (1968) Exercise and arterial pressure during simulated increase of gravity. Acta Physiol Scand 74:50-57

Lombardi F, Mortara A (1998) Heart rate variability and cardiac failure. Heart 80:213-214

Malliani A, Pagani M, Lombardi F, Cerutti S (1991) Cardiovascular neural regulation explored in the frequency domain. Circulation 84:482-492

O'Leary DD, Kimmerly DS, Cechetto AD, Shoemaker JK (2003) Differential effect of head-up tilt on cardiovagal and sympathetic baroreflex sensitivity in humans. Exp Physiol 88:769-774

Pagani M, Malliani A (2000) Interpreting oscillations of muscle sympathetic nerve activity and heart rate variability. J Hypertens 18:1709-1719

Pagani M, Lombardi F, Guzzetti S, Rimoldi O, Furlan R, Pizzinelli P, Sandrone G, Malfatto G, Dell'Orto S, Piccaluga E (1986) Power spectral analysis of heart rate and arterial pressure variabilities as a marker of sympatho-vagal interaction in man and conscious dog. Circ Res 59:178-193 
Pagani M, Montano N, Porta A, Malliani A, Abboud FM, Birkett C, Somers VK (1997) Relationship between spectral components of cardiovascular variabilities and direct measures of muscle sympathetic nerve activity in humans. Circulation 95:1441-1448

Parati G, Di Rienzo M, Bertinieri G, Pomidossi G, Casadei R, Groppelli A, Pedotti A, Zanchetti A, Mancia G (1988) Evaluation of the baroreceptor-heart rate reflex by 24-h intra-arterial blood pressure monitoring in humans. Hypertension 12:214-222

Pendergast DR, Olszowka A, Farhi LE (2012) Cardiovascular and pulmonary responses to increased acceleration forces during rest and exercise. Aviat Space Environ Med 83:488-495

Perini R, Veicsteinas A (2003) Heart rate variability and autonomic activity at rest and during exercise in various physiological conditions. Eur J Appl Physiol 90:317-325

Perini R, Orizio C, Baselli G, Cerutti S, Veicsteinas A (1990) The influence of exercise intensity on the power spectrum of heart rate variability. Eur J Appl Physiol 61:143-148

Piccirillo G, Cacciafesta M, Viola E, Santagada E, Nocco M, Lionetti M, Bucca C, Moisè A, Tarantini S, Marigliano V (2001) Influence of aging on cardiac baroreflex sensitivity determined noninvasively by power spectral analysis. Clin Sci 100:267-274

Rådegran G, Saltin B (1998) Muscle blood flow at onset of dynamic exercise in man. Am J Physiol Heart Circ Physiol 274:H314-H322

Remington JW, Wood EH (1956) Formation of peripheral pulse contour in man. J Appl Physiol 9:433-442

Robinson BF, Epstein SE, Beiser D, Braunwald E (1966) Control of heart rate by the autonomic nervous system: studies in man on the interrelation between baroreceptor mechanisms and exercise. Circ Res 19:400-411

Rohdin M, Linnarsson D (2002) Differential changes of lung diffusing capacity and tissue volume in hypergravity. J Appl Physiol 93:931-935

Rosenhamer G (1967) Influence of increased gravitational stress on the adaptation of cardiovascular and pulmonary function to exercise. Acta Physiol Scand Suppl 276:1-61

Rosenstock E, Cassuto Y, Zmora E (1999) Heart rate variability in the neonate and infant: analytical methods, physiological and clinical observations. Acta Paediatr 88:477-482
Rydlewska A, Jankowska EA, Ponikowska B, Borodulin-Nadzieja L, Banasiak W, Ponikowski P (2011) Changes in autonomic balance in patients with decompensated chronic heart failure. Clin Auton Res 21:47-54

Schneider S, Guardiera S, Kleinert J, Steinbacher A, Abel T, Carnahan $\mathrm{H}$, Strüder HK (2008) Centrifugal acceleration to $3 \mathrm{Gz}$ is related to increased release of stress hormones and decreased mood in men and women. Stress 11:339-347

Sigaudo D, Fortrat JO, Allevard AM, Maillet A, Cottet-Emard JM, Vouillarmet A, Hughson RL, Gauquelin-Koch G, Gharib C (1998) Changes in the sympathetic nervous system induced by 42 days of head-down bed rest. Am J Physiol Heart Circ Physiol 274:H1875-H1884

Strempel S, Schroeder C, Hemmersbach R, Boese A, Tank J, Diedrich A, Heer M, Luft FC, Jordan J (2008) Norepinephrine transporter inhibition alters the hemodynamic response to hypergravitation. $\mathrm{J}$ Appl Physiol 104:756-760

Tanaka K, Nishimura N, Sato M, Kanikowska D, Shimizu Y, Inukai Y, Abe C, Iwata C, Morita H, Iwase S, Sugenoya J (2013) Arterial pressure oscillation and muscle sympathetic nerve activity after 20 days of head-down bed rest. Auton Neurosci 177:266-270

Tank J, Baevski RM, Fender A, Baevski AR, Graves KF, Ploewka K, Weck M (2000) Reference values of indices of spontaneous baroreceptor reflex sensitivity. Am J Hypertens 13:268-275

Task force of the European Society of Cardiology and the North American Society of Pacing and Electrophysiology (1996) Heart rate variability. Standards of Measurement, physiological interpretation, and clinical use. Circulation 93:1043-1065

Traon AP, Sigaudo D, Vasseur P, Maillet A, Fortrat JO, Hughson RL, Gauquelin-Koch G, Gharib C (1998) Cardiovascular responses to orthostatic tests after a 42-day head-down bedrest. Eur J Appl Physiol Occup Physiol 77:50-59

Victor RG, Secher NH, Lyson T, Mitchell JH (1995) Central command increases muscle sympathetic nerve activity during intense intermittent isometric exercise in humans. Circ Res 76:127-131

Weippert M, Kumar M, Kreuzfeld S, Arndt D, Rieger A, Stoll R (2010) Comparison of three mobile devices for measuring R-R intervals and heart rate variability: Polar S810i, Suunto t6 and an ambulatory ECG system. Eur J Appl Physiol 109:779-786 